\title{
Rationale and design of a multicenter Chronic Kidney Disease (CKD) and at-risk for CKD electronic health records-based registry: CURE-CKD
}

Keith C. Norris ${ }^{1,2^{*}}$ D, O. Kenrik Duru', Radica Z. Alicic ${ }^{3,4}$, Kenn B. Daratha ${ }^{3}$, Susanne B. Nicholas ${ }^{1}$, Sterling M. McPherson ${ }^{3,5}$, Douglas S. Bell1, Jenny I. Shen ${ }^{1,6}$, Cami R. Jones ${ }^{3}$, Tannaz Moin ${ }^{1,7}$, Amy D. Waterman ${ }^{1}$, Joshua J. Neumiller ${ }^{8}$, Roberto B. Vargas ${ }^{9,10}$, Alex A. T. Bui ${ }^{1}$, Carol M. Mangione ${ }^{1}$, Katherine R. Tuttle ${ }^{3,4}$ and on behalf of the CURE-CKD investigators

\begin{abstract}
Background: Chronic kidney disease (CKD) is a global public health problem, exhibiting sharp increases in incidence, prevalence, and attributable morbidity and mortality. There is a critical need to better understand the demographics, clinical characteristics, and key risk factors for CKD; and to develop platforms for testing novel interventions to improve modifiable risk factors, particularly for the CKD patients with a rapid decline in kidney function.

Methods: We describe a novel collaboration between two large healthcare systems (Providence St. Joseph Health and University of California, Los Angeles Health) supported by leadership from both institutions, which was created to develop harmonized cohorts of patients with CKD or those at increased risk for CKD (hypertension/HTN, diabetes/DM, pre-diabetes) from electronic health record data.

Results: The combined repository of candidate records included more than 3.3 million patients with at least a single qualifying measure for CKD and/or at-risk for CKD. The CURE-CKD registry includes over 2.6 million patients with and/or at-risk for CKD identified by stricter guide-line based criteria using a combination of administrative encounter codes, physical examinations, laboratory values and medication use. Notably, data based on race/ethnicity and geography in part, will enable robust analyses to study traditionally disadvantaged or marginalized patients not typically included in clinical trials.

Discussion: CURE-CKD project is a unique multidisciplinary collaboration between nephrologists, endocrinologists, primary care physicians with health services research skills, health economists, and those with expertise in statistics, bio-informatics and machine learning. The CURE-CKD registry uses curated observations from real-world settings across two large healthcare systems and has great potential to provide important contributions for healthcare and for improving clinical outcomes in patients with and at-risk for CKD.
\end{abstract}

Keywords: Chronic kidney disease, Electronic health records, Healthcare systems, Hypertension, Diabetes, Prediabetes, Registry, Study design

\footnotetext{
* Correspondence: KCNorris@mednet.ucla.edu

'David Geffen School of Medicine at University of California, Los Angeles, CA

90095, USA

${ }^{2}$ UCLA Department of Medicine, Division of General Internal Medicine, 1100

Glendon Ave. Suite 900, Los Angeles, CA 90024, USA

Full list of author information is available at the end of the article
}

C The Author(s). 2019 Open Access This article is distributed under the terms of the Creative Commons Attribution 4.0 International License (http://creativecommons.org/licenses/by/4.0/), which permits unrestricted use, distribution, and reproduction in any medium, provided you give appropriate credit to the original author(s) and the source, provide a link to the Creative Commons license, and indicate if changes were made. The Creative Commons Public Domain Dedication waiver (http://creativecommons.org/publicdomain/zero/1.0/) applies to the data made available in this article, unless otherwise stated. 


\section{Background}

Chronic kidney disease (CKD) is a major public health problem affecting an estimated 30 million United States (US) adults and is the 9th leading cause of death in the US [1]. Patients with CKD suffer from high rates of premature morbidity including cardiovascular diseases and progression to end stage kidney disease (ESKD) as well as premature mortality [1]. In addition, CKD imposes a high financial burden accounting for over 7\% of Medicare spending on ESKD patients per year, while less than 1\% of the Medicare population are ESKD patients [2]. Thus, the care of CKD patients is a national legislative priority [35]. Despite several strategies to improve CKD prevention, early intervention and outcomes, progress has been slow. Multiple factors can influence clinical outcomes for patients with CKD, including but not limited to underlying predisposing medical conditions, genetic risks, environmental, sociocultural factors and others such as healthcare systems and access to healthcare [6-12]. These factors may also lead to disparities in incidence and prevalence across different patient subgroups while also limiting optimal care for all patients [6-12].

The Center for Kidney Disease Research, Education and Hope (CURE-CKD) registry was developed to capitalize on a unique opportunity to integrate and harmonize electronic health record (EHR) data on 9.9 million patients treated since 2006 within two large healthcare systems using key elements outlined by Goldstein et al. [13] and Navaneethan and colleagues [14]. The CURE-CKD registry is intended to provide unique insights into real-world clinical care and outcomes from a broad repository of over 3.3 million candidate patients with a single entry-point CKD criteria or at-risk for CKD, and a more select registry of over 2.6 million patients following stricter guide-line-based CKD or at-risk CKD criteria. The objectives of the CURE-CKD registry are to: 1) collaborate to develop standardized data structures for analysis and to harmonize two large and distinct datasets; 2) identify patients with CKD or at increased risk for CKD (hypertension (HTN), diabetes (DM), and prediabetes) from EHR data; 3) support sitecombined and site-specific comparative analyses of key clinical issues including but not limited to, the prevalence of testing for CKD using laboratory measurements including estimated glomerular filtration rate (eGFR), urine albumin-to-creatinine ratio (UACR) and total urine protein-to-creatinine ratio (UPCR); the ability to examine eGFR decline to identify high-risk patients; the impact of evidence-based ambulatory care such as adherence to recommended pharmacotherapy, blood pressure and DM control on delaying eGFR decline and reducing rates of hospitalizations and re-hospitalizations; and 4) identify subgroups traditionally beset with disparities in CKD and at-risk for CKD outcomes (e.g. racial/ ethnic minority, low income, rural dwelling/geolocation) and develop strategies to eliminate disparities in care. Given the origins of this data-rich registry, several unique analytic and decision-making methodologies were developed to produce a database representative of real-world data but also readily amenable to scientific inquiry. The goal of this report is to describe the CURE-CKD registry design and outline proposed analytic methods.

\section{Methods/design \\ Ethical statement}

Independent institutional review board (IRB) approvals were obtained from the Providence Saint Joseph Health (PSJH Health) and the University of California, Los Angeles Health (UCLA Health) healthcare systems (Providence IRB: 2043 CURE-CKD: CKD and At-Risk CKD Registry, and UCLA IRB: 15-001993 Assessing the Prevalence and Management of Chronic Kidney Disease). The data in the repository (single entry-point criteria for CKD or at-risk for CKD) and registry (strict CKD or at-risk CKD criteria) are maintained in accordance with the principles of the Declaration of Helsinki and local regulatory requirements. Informed consent was not required as this is a limited dataset and Health Insurance Portability and Accountability waivers are in place.

\section{Study design}

PSJH and UCLA Health are not-for-profit healthcare systems that established a collaborative data use agreement to provide the framework for data sharing and stewardship in a secure electronic environment. PSJH operates 829 clinics and 50 hospitals in Washington, Oregon, Alaska, Montana, and California. UCLA Health has 170 clinics and 4 hospitals (with admitting privileges at $>15$ hospitals) in Southern California. Each system uses the Epic EHR (Epic System Corporation), from which data for the repository and resulting registry were extracted. The larger repository and the CURE-CKD registry are updated annually to provide additional longitudinal data for existing participants, and to identify new participants who meet inclusion/exclusion criteria.

\section{Data validation and harmonization}

Clinical (e.g. laboratory measurements, physical measurements, and medication records) and administrative encounter data were validated and harmonized between the PSJH and UCLA Health systems to create a single EHR-based dataset, suitable for analyses in this ongoing, observational, multicenter study. Data structures were proposed, discussed and approved by a multidisciplinary team of investigators at weekly meetings and twiceyearly in-person meetings over a two-year period. The disciplines represented in this collaboration included 
collaborators with expertise in clinical nephrology, endocrinology, general internal medicine, health services research, pharmaceutical sciences, health disparities, health economics, biostatistics, big database construction, machine learning and bioinformatics.

CURE-CKD data analysts harmonized and linked data structures, and clinicians conducted internal and interinstitutional validation of EHR laboratory values, medication records, and administrative encounter codes [14]. When discordance could not be resolved, the issues were brought to CURE-CKD weekly team meetings for discussion and resolution. UCLA Health and PSJH Health datasets were fully harmonized and maintained as both merged and independent datasets.

\section{Participants and inclusion/exclusion criteria}

Repository participants $(N=3,364,801)$ were identified from EHR laboratory and physical measurements, administrative codes and medication records from inpatient, outpatient and ambulatory settings (Fig. 1). Repository individuals were identified by a series of criteria including laboratory tests, with any eGFR (CKDEPI) measurement $<60 \mathrm{~mL} / \mathrm{min} / 1.73 \mathrm{~m}^{2}$; any UACR $\geq 30$ $\mathrm{mg} / \mathrm{g}$; any UPCR $\geq 150 \mathrm{mg} / \mathrm{g}$; any hemoglobin A1c (HbA1c) $\geq 5.7 \%$; any random blood glucose $\geq 140 \mathrm{mg} / \mathrm{dL}$; or fasting blood glucose $\geq 100 \mathrm{mg} / \mathrm{dL}$. Individuals with any diagnostic code for CKD, HTN, DM and prediabetes were identified as repository participants. Extracted physical measurements identified participants as repository eligible with any systolic or diastolic blood pressure $\geq 140 \mathrm{~mm} \mathrm{Hg}$ or $\geq 90 \mathrm{~mm} \mathrm{Hg}$, respectively. Finally, medication records were examined, with individuals prescribed anti-hyperglycemic agents identified as repository participants.

Repository patients were then screened for inclusion in the CURE-CKD registry, following clinical practice guidelines (Table 1). Individuals with laboratory evidence of CKD (two measurements of eGFR $<60 \mathrm{~mL} /$ $\mathrm{min} / 1.73 \mathrm{~m}^{2}$, UACR $\geq 30 \mathrm{mg} / \mathrm{g}$, or UPCR $\geq 150 \mathrm{mg} / \mathrm{g}$ at least 90 days apart), or any encounter with a diagnostic code for CKD were entered into the registry $(N=618$, 655). For adults eGFR was calculated using the Chronic Kidney Disease Epidemiology (CKD-EPI) equation (15, 16) and for children with CKD ( $<18$ years) we use the bedside Schwartz equation [17]. Individuals with physical evidence (two measurements of systolic or diastolic blood pressure $\geq 140 \mathrm{~mm} \mathrm{Hg}$ or $\geq 90 \mathrm{~mm} \mathrm{Hg}$, respectively at least 14 days apart) or any encounter with a diagnostic code for HTN were entered into the registry $(N=1,915$, 245; please note that patients can have more than one disorder so the sample sizes are not mutually exclusive). Individuals were identified and entered into the registry $(N=91,310)$ if there was laboratory evidence of DM (one measurement of HbA1c $\geq 6.5 \%$; two measurements of random or fasting blood glucose $\geq 200 \mathrm{mg} / \mathrm{dL}$ or $\geq 126$ $\mathrm{mg} / \mathrm{dL}$, respectively at least 1 day, but not more than 2 years apart); one inpatient encounter or at least two outpatient encounters with a diagnostic code of DM; or at least one prescription for anti-hyperglycemic medication. Anti-hyperglycemic medications were identified by therapeutic classes (insulin, sulfonylurea, thiazolidinedione, dipeptidyl peptidase 4, glucagon-like peptide 1 , sodium glucose co-transporter 2 , and metformin). Antihypertensive, and nephrotoxic medications (nonsteroidal anti-inflammatory drugs (NSAIDs) and proton pump inhibitors (PPIs) were also identified. Individuals prescribed metformin with a diagnostic code indicating polycystic ovarian syndrome, with no other evidence of DM or prediabetes inclusion criteria were subsequently removed from the registry. All included medications were manually reviewed and verified by the study pharmacist and/or clinical team members. Individuals with laboratory evidence of prediabetes (one measurement of HbA1c between 5.7-6.4\%; two measurements of random or fasting blood glucose between 140 and 199 $\mathrm{mg} / \mathrm{dL}$ or $100-125 \mathrm{mg} / \mathrm{dL}$, respectively at least 1 day, but not more than 2 years apart); or any encounter with a diagnostic code indicating prediabetes were entered into the registry $(N=1,026,629)$.

\section{Characterizing registry participants}

Registry patients have been characterized by clinical and demographic characteristics [21]. Additionally, registry patients have been classified by geography, including state and urban versus rural status. A majority of patients in the registry $(N=2,625,963)$ currently reside in the states of Washington (41.6\%), California (31.5\%), Oregon (17.2\%), Alaska (3.4\%) and Montana (2.6\%). Patient resident zip codes were mapped to Rural-Urban Commuting Area (RUCA) codes, following category C (https://depts.washington.edu/uwruca/ ruca-uses.php). Registry patients have been classified as urban (87.5\%) and rural (11.4\%). Any individuals without a zip code $(1.1 \%)$ were not assigned a RUCA code and were not classified as either living in a rural or an urban area.

\section{Planned CURE-CKD registry analyses \\ Outcomes assessment}

The CURE-CKD study team will assess changes in laboratory and physical markers including eGFR, UACR/ UPCR, and blood pressure, as well as adherence to effective and de-implementation of ineffective strategies/ medicines over time in registry participants. Both kidney replacement therapy (hemodialysis, peritoneal dialysis, kidney transplant) and mortality will be obtained by linking the CURE-CKD registry to the United States Renal Data System (USRDS) Coordinating Center 


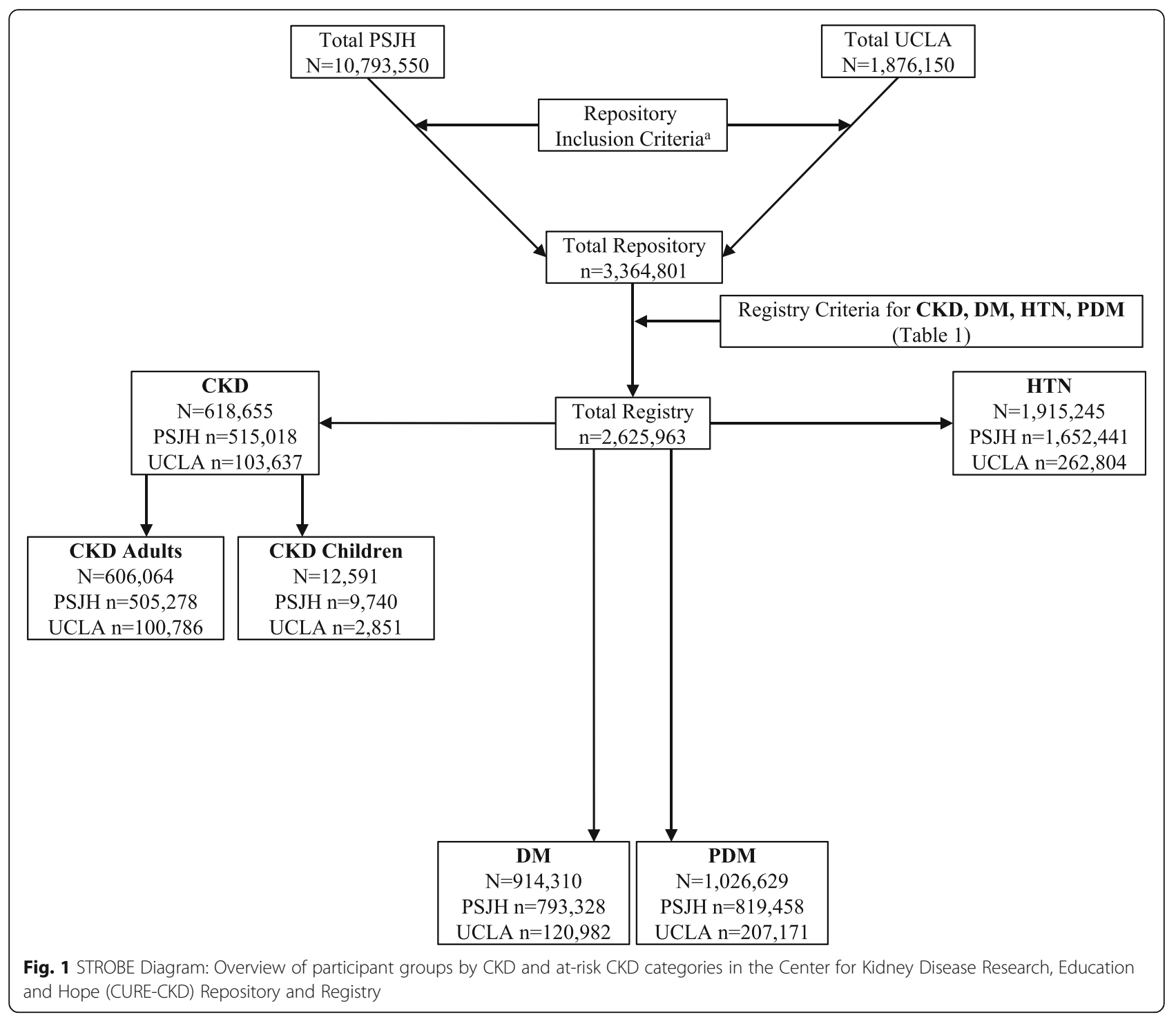

through a USRDS-merged dataset agreement for release of data with limited personally identifiable information. The USRDS provides data solely for the conduct of legitimate and approved biomedical, cost-effectiveness, and other economic research. To obtain accurate mortality data, the CURE-CKD registry will link to the National Death Index provided by the Centers for Disease Control and Prevention, the Social Security Death Master File, and to state death indices for the states served by PSJH Health and UCLA Health.

\section{Traditional statistical analyses}

Planned statistical approaches include descriptive analyses of the dataset as combined and as two distinct health systems. Statistical modeling approaches such as linear regression, generalized estimating equations, and linear mixed models (LMMs) will be used to investigate change in eGFR over time. LMMs have been shown to be the most robust approach to address the varying number and dispersion of time points and differences in duration of follow-up, especially in settings with high drop-out rates (e.g. slope of eGFR decline accounting for initiation of kidney replacement therapy and death) [22]. Notably, such a framework also allows for the examination of non-linear patterns of change over time (e.g., quadratic change, piecewise change) and lends itself well to extensions of LMMs such as finite growth mixture modeling for the examination of population-level heterogeneity into distinct, empirically-driven sub-groups of meaningful change. LMMs will be used in multivariable models to examine differences in eGFR trajectories, change in UACR/UPCR, and other clinical parameters, controlling for baseline demographics, clinical comorbidities, location (using small area analyses with geocoded data) and time-varying covariates (systolic blood pressure, HbA1c, use of NSAIDs and angiotensin 
Table 1 Inclusion Criteria for the CURE-CKD Registry

\begin{tabular}{ll}
\hline Chronic Kidney Disease & 1. At least two eGFR (CKD-EPI equation or Schwartz) measurements $<60 \mathrm{~mL} / \mathrm{min} / 1.73 \mathrm{~m}^{2}$ at least 90 days apart, or \\
[15-17] & 2. At least two laboratory measurements at least 90 days apart in which albuminuria was indicated; albumin to creatinine \\
ratio $\geq 30 \mathrm{mg} / \mathrm{g}$, or total urine protein $\geq 150 \mathrm{mg} / \mathrm{g}$, or \\
3. At least one encounter (inpatient or outpatient) with an ICD-9 or ICD-10 diagnosis code indicating chronic kidney dis- \\
ease is present \\
1. At least two vital sign measurements $>14$ days apart with a systolic blood pressure $\geq 140 \mathrm{~mm} \mathrm{Hg}$ or diastolic blood \\
pressure $\geq 90 \mathrm{~mm} \mathrm{Hg}$, or \\
2. At least one encounter (inpatient or outpatient) with an ICD-9 or ICD-10 diagnosis code indicating hypertension is \\
present
\end{tabular}

eGFR estimated glomerular filtration rate, CKD Chronic Kidney Disease, ICD-9/ICD-10 International Classification of Diseases, 9th Revision/10th Revision, $H b$ hemoglobin, PCOS Polycystic ovarian syndrome, CKD-EPI Chronic Kidney Disease Epidemiology Collaboration

converting enzyme inhibitors (ACEI) or angiotensin II receptor blockers (ARB), both overall and in known disparate subgroups (e.g. age, race/ethnicity, gender, socioeconomic status, rurality). Time to event analysis (Kaplan-Meier and Cox proportional hazard regression models) will be used to examine CKD and at-risk CKD differences in rates reaching clinically significant declines in eGFR, ESKD and mortality, progression to incident DM and others. Competing risk analyses will be conducted when appropriate given both dialysis and kidney transplant compete with the outcome of death.

\section{Machine learning analyses}

In addition to traditional regression modeling of outcomes, machine learning methods will be used to construct dynamic belief networks (DBNs) to model changes in eGFR and to estimate the probability of developing advanced CKD over time. The DBNs will examine factors contributing to eGFR over time, and differences in eGFR trajectories between subgroups. The DBN's predictive performance will be compared against existing validated CKD risk models [23-27] and other machine learning-based methods. In addition, the DBN-based models will be tested to determine if the models correctly predict changes in eGFR trajectory by assessing predictions at different time points relative to known outcomes. Internal validity of the DBN will be assessed by its capability to predict the change in eGFR trajectory based on past observations, and the external validity by cross-testing between differing sites (Fig. 2), with content expert review of transportability of findings across sites and to external populations. Model performance will be tested in terms of discrimination (assessing the model's ability to distinguish among patients with different outcomes) and calibration (c-statistics, comparing observed and predicted event rates for groups of patients).

\section{Discussion}

The CURE-CKD registry will provide new approaches to fill knowledge gaps and guide the development of better management strategies for patients with and at-risk for CKD. The large volume of data, with over 3.3 million unique patients available in the combined repository and over 2.6 million patients in the registry, offers an opportunity to conduct a myriad of health services-related studies (e.g. epidemiological research, machine learning, clinical decision support, team-based interventions, value-based care, reduction in health disparities) for this patient population and traditionally under-represented disadvantaged sub-populations (e.g., American Indian or Asian American populations, rural-dwelling populations) in diverse real-world settings [28].

The CURE-CKD study team will examine multiple aspects of evidence-based care that have not been extensively validated using real-world data. For instance, uncertainty persists regarding the appropriate blood pressure target levels for CKD patients [29, 30]. Some studies support a lower target blood pressure goal [31, 32], some have found no relationship between CKD-related outcomes and blood pressure [33], while others have found blood pressure-related outcomes vary by the severity of UACR/UPCR, CKD stage, presence of DM, and other factors [34-38]. These conflicting findings have led to consternation 

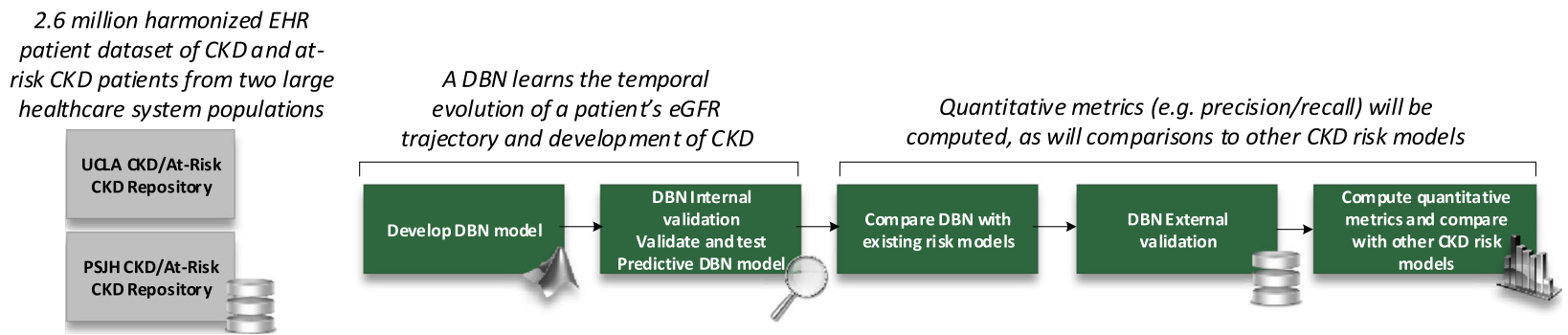

Fig. 2 Summary of Dynamic Belief Network Model

in the clinical care of CKD patients. The recent 2017 American Heart Association's current blood pressure guideline recommends the goal blood pressure $<130$ / $80 \mathrm{~mm} \mathrm{Hg}$ for all CKD patients without consideration of CKD stage [39]. Prospective studies using large real-world datasets such as the CURE-CKD registry, may better assist with informing evidence-based care for patients with and at-risk for CKD, including optimal targets for different patient subgroups (e.g. those with comorbid conditions, different CKD stages). The use of NSAIDs [40-42], PPIs [43-46], and smoking [47-49] have been reported to be associated with CKD onset, progression, and poor outcomes. The CURE-CKD registry is substantially powered to examine the association of these and other CKD risk factors in relation to several CKD protective or resilience factors stratified by patient subgroups. It is also well positioned to investigate the contributions of DM, prediabetes and/or HTN to CKD incidence, which will enable the development of clearer approaches to practice-based algorithms for promotion of early detection and intervention for CKD as well as more accurate prediction of disease progression.

In health disparate populations such as minority racial/ethnic groups, there is a paucity of data on the role of major modifiable risk factors such as protective and potentially harmful medications, smoking, body weight, and lifestyle in CKD-related outcomes in real-world settings. For instance, while prior studies found the degree of blood pressure lowering with ACEI or ARB use was greater in Whites than in Blacks [50] leading to low use of ACEI/ARBs in Blacks, the African American Study of Kidney Disease and Hypertension demonstrated that inhibition of the renin-angiotensinaldosterone system was the most effective class of blood pressure therapy in improving CKD and mortality outcomes in Blacks with hypertension-related CKD [51], and has led to an improvement in the practice of low ACEI/ARB use in Blacks. Further exploration of ACEI/ARBs in clinical outcomes for Blacks and other racial/ethnic groups in clinical practice is warranted. The CURE-CKD registry provides a large, real-world longitudinal dataset to evaluate conflicting results from trials with observations in a clinical practice setting. Developing a better understanding of key modifiable risk factors and their interaction with existing clinical targets could lead to new anti-hypertensive medication recommendations for select subgroups of patients with CKD and especially for those patients with rapid progression of eGFR decline.

The collaborative nature of the CURE-CKD registry has inherent barriers that must be overcome in the development of inter-institutional EHR-based registries. In general terms, these limitations may include data quality, data inconsistency or stability (e.g. lack of data standards, variations across laboratories), the validation of data and other analytical limitations (e.g. missing data, potential over-fitting of prediction models, multiple comparisons, risk of false-positive associations), trust building and the development of data use agreements that protect all collaborative institutions and the inherent limitations of observational data [52]. More specific limitations include differences in documentation practices that exist across and between healthcare systems [53] even with a similar EHR platform. Additional limitations for inter-institutional registries such as the CURE-CKD registry includes attrition rates that may vary regionally due to insurance coverage, rates of poverty, implementation or de-implementation of the Affordable Care Act and other state or national healthcare initiatives.

By contrast, the CURE-CKD registry has many strengths. These include a two-year preparation period to create a robust inter-institutional registry using close and thoughtful collaboration to define common structures and to identify and synchronize data elements. The initial iteration of the registry includes longitudinal data over an 11-year period, from 2006 to 2017, with annual updates. Another strength is the use of laboratory and clinical data including disease-specific (e.g. DM, prediabetes) medications to supplement administrative encounter data, rigorous data curation and longitudinal observation of a large number of registry participants. For longitudinal assessment of major 
clinical outcomes, the CURE-CKD registry will be linked with national and state death indices and the USRDS to ascertain ESKD events and Medicare administrative data for hospitalization events. Also, the proportion of patients with HTN (73\%) and DM (31\%) in the registry are similar to the participants in the Kidney Early Evaluation Program [54,55] providing a level of external validation. To address the low use of administrative encounter codes especially for conditions such as CKD, HTN, DM, prediabetes, and other comorbidities, CURE-CKD inclusion criteria consisted of clinical and laboratory data as well as medication records. Finally, it is important to note that real-world observations from EHRs can be used to supplement randomized trials to inform best practices and clinical guidelines as well as to generate CKD- and at-risk for CKD-based interventions. In the future, this longitudinal data source combined with statistical methods such as propensity score matching that identify robust comparator groups, will be an efficient learning lab to study the impact of real world system level interventions designed to prevent the onset of CKD in high risk populations and to reduce the rate of persons with rapid eGFR decline among those with CKD. To conduct research that can improve health equity, it will never be possible to conduct randomized controlled trials in all the groups at greatest risk, so approaches that use robust real-world data systems with unbiased comparator groups such as CURE-CKD hold promise for identifying the interventions that reduce disparities the most.

In summary, the development of novel methods to improve the identification and early intervention for patients with or at-risk for CKD has remained a challenge [56]. Big data analytics from EHRs have tremendous potential to improve the quality and outcomes of care for patients with and at-risk for CKD. With the emerging addition of social determinants of health and precision medicine (i.e. omics) markers to patients in large healthcare systems, the amount of data available to inform CKD care and research will soon be exponential in nature. A combination of traditional and machine learning-based analytic approaches will be critical to appropriately analyze these rapidly growing datasets with careful interpretation to retain their relevance for patient care, clinical management, and performance improvement. The CURE-CKD registry not only includes comprehensive administrative encounter data, but also includes a vast amount of clinical and laboratory measurements, as well as pharmacy and procedure records. The CURE-CKD study team is well positioned to conduct robust longitudinal analyses that will include important subgroups, with much greater power than most existing sources to identify subgroup-level differences.
CURE-CKD has the potential to provide important contributions for healthcare in patients with and at-risk for CKD using observations from real-world settings and to provide timely opportunity to respond to the recent Executive Order on Advancing American Kidney Health [57].

\section{Abbreviations}

ACEl: Angiotensin Converting Enzyme Inhibitor; ARB: Angiotensin II Receptor Blockers; CKD: Chronic Kidney Disease; CURE-CKD: Center for Kidney Disease Research, Education and Hope; DBNs: Dynamic Belief Networks; DM: Diabetes Mellitus; eGFR: Estimated Glomerular Filtration Rate; EHR: Electronic Health Record; ESKD: End-Stage Kidney Disease;

HbA1c: Hemoglobin A1c; HTN: Hypertension; IRB: Institutional Review Board; LMMs: Linear Mixed Models; NSAIDs: Nonsteroidal Anti-Inflammatory Drugs; PPIs: Proton Pump Inhibitors; PSJH Health: Providence Saint Joseph Health; RUCA: Rural-Urban Commuting Area; UACR: Urine Albumin-to-Creatinine Ratio; UCLA Health: University of California, Los Angeles Health; UPCR: Urine Protein-to-Creatinine Ratio; US: United States; USRDS: United States Renal Data System

\section{Acknowledgements}

Additional CURE-CKD investigators - Karen Agnew; Celestina Barbosa-Leiker; Ann Cooper; Mark Gargett; Marianne Zachariah; Peter Kim; Celestina BarbosaLeiker; Carol. Miceli; Robert W. Follett; Theona Tacorda; Susan Ettner; David Elashoff.

We also want to thank the many patients within the Providence Saint Joseph Health and University of California, Los Angeles Health Systems. A special thanks to Carol Miceli, Robert Follett, and Theona Tacorda for their diligent extraction of data from EHRs and Art Gongora for his administrative support to the CURE-CKD Program. And a special thanks to the Providence Saint Joseph Health (led by Melody Craff, PhD, MBA, MD) and the University of California, Los Angeles Health (led by Johnesse Spisso, MPA) healthcare systems for their unwavering support to help make this project possible.

\section{Authors' contributions}

KRT and KCN led project development for CURE-CKD from concept inception through data acquisition, curation, analyses, interpretation, and drafting the manuscript. RZA, OKD, CRJ, KBD, SBN, SMM, DSB, JIS, AATB, ADW, TM, JJN and RBV contributed to data acquisition, curation, analyses, and drafting the manuscript. CMM made significant contributions to concept inception, data interpretation, and drafting the manuscript. All authors have read and approved the manuscript.

\section{Funding}

Creation of the CURE-CKD registry was supported by institutional grants from PSJH and UCLA Health. In addition KRT is supported by NIH grants 4UL1TR00426-10, 1U2CDK114886-01, 5UM1DK100846-03, 2U01DK10086-07, 1U54DK083912, 2UC4DK101108-02, and CDC grant 75D301-19-Q-69877; RZA is supported by NIH grants 5UM1DK100846-03, 2U01DK10086-07, and CDC grant 75D301-19-Q-69877; CRJ is supported by CDC grant 75D301-19Q-69877; KBD is supported by CDC grant 75D301-19-Q-69877; SBN is supported by NIH/NCATS grant UL1TRR001881 and the Terasaki Institute; SMM is supported by NIH grants P20MD006871, UG1DA013714, R01EY027476, N44DA162246, R01AA022070, R01AA020248, P60AA026112, R41AA026793, N44DA171210, R01AG042467, VA grant 101HX002518 and CDC grant 75D301-19-Q-69877; JIS is supported by NIH grant K23DK103972; DB is supported by NIH grant UL1TR000124; TM is supported by VA grants QUE 15272, QUE 15-286, CSP\#2002. ADW is supported by NIH grant UL1TR000124 and the Terasaki Institute. OKD, CMM and $\mathrm{KCN}$, are supported by $\mathrm{NIH}$ grants UL1TR000124 and P30AG021684 and the Terasaki Institute. OKD, CMM, and TM are supported by CDC grant U18-DP-006128, NIH grant R18-DK-10546401 and PCORI grant 123543. CMM's work on this project is partially supported by the Barbara A. Levey and Gerald S. Levey Endowed Chair. 


\section{Ethics approval and consent to participate}

All study procedures were approved by Providence St. Joseph Health (PSJH; Washington, Montana, Oregon, Alaska, California) and the University of California, Los Angeles (UCLA; California) Health Institutional Review Boards that operate in full accordance with institutional, state, and national policies and regulations for human research participants and the principles of the Declaration of Helsinki. The Institutional Review Boards determined that obtaining written informed consent was not required due to use of a limited dataset. Data use agreements between PSJH and UCLA Health were established to provide the necessary framework for data sharing, stewardship, and security.

\section{Consent for publication}

N/A

\section{Competing interests}

The authors declare that they have no competing interests.

\section{Author details}

'David Geffen School of Medicine at University of California, Los Angeles, CA 90095, USA. ${ }^{2}$ UCLA Department of Medicine, Division of General Internal Medicine, 1100 Glendon Ave. Suite 900, Los Angeles, CA 90024, USA. ${ }^{3}$ Providence St. Joseph Health, Providence Medical Research Center, Spokane, Washington, USA. ${ }^{4}$ University of Washington School of Medicine, Seattle, Washington, USA. ${ }^{5}$ Washington State University Elson S. Floyd College of Medicine, Spokane, Washington, USA. 'os Angeles Biomedical Research Institute at Harbor-UCLA Medical Center, Torrance, CA, USA. 7 VA Greater Los Angeles, Los Angeles, USA. ${ }^{8}$ Washington State University College of Pharmacy and Pharmaceutical Sciences, Spokane, USA. ${ }^{9}$ Charles R. Drew University of Medicine and Science, Los Angeles, USA. ${ }^{10}$ RAND Corporation, Santa Monica, CA, USA.

\section{Received: 5 September 2019 Accepted: 12 September 2019}

\section{Published online: 20 November 2019}

\section{References}

1. Murphy SL, Kochanek KD, Xu JQ, Heron M. Deaths: Final data for 2012 National vital statistics reports; vol 63 no 9. Hyattsville: National Center for Health Statistics; 2015.

2. United States Renal Data System. 2017 USRDS annual data report: Epidemiology of kidney disease in the United States. Bethesda: National Institutes of Health, National Institute of Diabetes and Digestive and Kidney Diseases; 2017.

3. Erickson KF, Winkelmayer WC. Evaluating the evidence behind policy mandates in US Dialysis care. J Am Soc Nephrol. 2018;29(12):2777-9. https:// doi.org/10.1681/ASN.2018090905.

4. Rettig RA. Special treatment--the story of Medicare's ESRD entitlement. New Eng J Med. 2011;364(7):596-8. https://doi.org/10.1056/NEJMp1014193.

5. Rettig RA, Norris K, Nissenson AR. Chronic kidney disease in the United States: a public policy imperative. Clin J Am Soc Nephrol. 2008;3(6):1902-10. https://doi.org/10.2215/CJN.02330508.

6. Nicholas SB, Kalantar-Zadeh K, Norris KC. Racial disparities in kidney disease outcomes. Semin Nephrol. 2013;33(5):409-15. https://doi.org/10.1016/j. semnephrol.2013.07.002.

7. Norris K, Nissenson AR. Race, gender, and socioeconomic disparities in CKD in the United States. J Am Soc Nephrol. 2008;19(7):1261-70. https://doi.org/ 10.1681/ASN.2008030276.

8. Powe NR. Let's get serious about racial and ethnic disparities. J Am Soc Nephrol. 2008;19(7):1271-5. https://doi.org/10.1681/ASN.2008040358.

9. Harding K, Mersha TB, Vassalotti JA, Webb FA, Nicholas SB. Current state and future trends to optimize the care of chronic kidney disease in African Americans. Am J Nephrol. 2017;46(2):176-86. https://doi.org/10.1159/ 000479481.

10. Norton JM, Moxey-Mims MM, Eggers PW, Narva AS, Star RA, Kimmel PL, et al. Social determinants of racial disparities in CKD. J Am Soc Nephrol. 2016;27(9):2576-95. https://doi.org/10.1681/ASN.2016010027.

11. Kimmel PL, Fwu CW, Abbott KC, Ratner J, Eggers PW. Racial disparities in poverty account for mortality differences in US Medicare beneficiaries. SSM - Population Health. 2016;2:123-9.
12. Laster M, Shen Jl, Norris KC. Kidney Disease Among African Americans: A Population Perspective. Am J Kidney Dis. 2018;72(5s1):S3-s7. https://doi.org/ 10.1053/j.ajkd.2018.06.021.

13. Goldstein BA, Navar AM, Pencina MJ. Risk prediction with electronic health records: the importance of model validation and clinical context. JAMA Cardiol. 2016;1 (9):976-7. https://doi.org/10.1001/jamacardio.2016.3826.

14. Navaneethan SD, Jolly SE, Schold JD, Arrigain S, Saupe W, Sharp J, et al. Development and validation of an electronic health record-based chronic kidney disease registry. Clin J Am Soc Nephrol. 2011;6(1):40-9. https://doi. org/10.2215/CJN.04230510.

15. Matsushita K, Mahmoodi BK, Woodward M, Emberson JR, Jafar TH, Jee SH, et al. Comparison of risk prediction using the CKD-EPI equation and the MDRD study equation for estimated glomerular filtration rate. JAMA. 2012; 307(18):1941-51. https://doi.org/10.1001/jama.2012.3954.

16. Kidney Disease: Improving Global Outcomes (KDIGO) CKD Work Group. KDIGO 2012 Clinical practice guideline for the evaluation and Management of Chronic Kidney Disease. Kidney Int. 2013;3(1):1-150.https://www. sciencedirect.com/journal/kidney-international-supplements/vol/3/issue/1.

17. Schwartz GJ, Munoz A, Schneider MF, Mak RH, Kaskel F, Warady BA, et al. New equations to estimate GFR in children with CKD. J Am Soc Nephrol. 2009;20(3):629-37. https://doi.org/10.1681/ASN.2008030287.

18. James PA, Oparil S, Carter BL, Cushman WC, Dennison-Himmelfarb C, Handler J, et al. 2014 evidence-based guideline for the management of high blood pressure in adults: report from the panel members appointed to the eighth joint National Committee (JNC 8). JAMA. 2014;311(5):507-20. https://doi.org/10.1001/jama.2013.284427.

19. Association AD. 2. Classification and diagnosis of diabetes: standards of medical care in diabetes_2019. Diabetes Care. 2019;42(Supplement 1):S1328. https://doi.org/10.2337/dc19-S002.

20. Nichols GA, Desai J, Elston Lafata J, Lawrence JM, O'Connor PJ, Pathak $\mathrm{RD}$, et al. Construction of a multisite DataLink using electronic health records for the identification, surveillance, prevention, and management of diabetes mellitus: the SUPREME-DM project. Prev Chronic Dis. 2012;9:E110.

21. Tuttle KR, Alicic RZ, Kenrik Duru O, Jones CR, Daratha KB, Nicholas SB, McPherson SM, Neumiller JJ, Bell DS, Mangione CM, Norris KC. Clinical Characteristics and Risk Factors for Chronic Kidney Disease among Adults and Children: An Analysis from the CURE-CKD Registry. JAMA Network Open.

22. Leffondre K, Boucquemont J, Tripepi G, Stel VS, Heinze G, Dunkler D. Analysis of risk factors associated with renal function trajectory over time: a comparison of different statistical approaches. Nephrol Dial Transplant. 2015; 30(8):1237-43. https://doi.org/10.1093/ndt/gfu320.

23. Johnson ES, Thorp ML, Platt RW, Smith DH. Predicting the risk of dialysis and transplant among patients with CKD: a retrospective cohort study. Am J Kidney Dis. 2008:52(4):653-60. https://doi.org/10.1053/j.ajkd.2008.04.026.

24. Landray MJ, Emberson JR, Blackwell L, Dasgupta T, Zakeri R, Morgan MD, et al. Prediction of ESRD and death among people with CKD: the chronic renal impairment in Birmingham (CRIB) prospective cohort study. Am J Kidney Dis. 2010;56(6):1082-94. https://doi.org/10.1053/j.ajkd.2010.07.016.

25. Tangri N, Stevens LA, Griffith J, Tighiouart H, Djurdjev O, Naimark D, et al. A predictive model for progression of chronic kidney disease to kidney failure. JAMA. 2011;305(15):1553-9. https://doi.org/10.1001/jama. 2011.451.

26. Schroeder EB, Yang X, Thorp ML, Arnold BM, Tabano DC, Petrik AF, et al. Predicting 5-year risk of RRT in stage 3 or 4 CKD: development and external validation. Clin J Am Soc Nephrol. 2017;12(1):87-94. https://doi.org/10.2215/ CJN.01290216.

27. Tangri N, Inker LA, Hiebert B, Wong J, Naimark D, Kent D, et al. A dynamic predictive model for progression of CKD. Am J Kidney Dis. 2017;69(4):51420. https://doi.org/10.1053/j.ajkd.2016.07.030.

28. Tuot DS, McCulloch CE, Velasquez A, Schillinger D, Hsu CY, Handley M, et al. Impact of a primary care CKD registry in a US public safety-net health care delivery system: a pragmatic randomized trial. Am J Kidney Dis. 2018;72(2): 168-77. https://doi.org/10.1053/j.ajkd.2018.01.058.

29. Weiner DE, Tighiouart H, Levey AS, Elsayed E, Griffith JL, Salem DN, et al. Lowest systolic blood pressure is associated with stroke in stages 3 to 4 chronic kidney disease. J Am Soc Nephrol. 2007;18(3):960-6.

30. Kovesdy CP, Lu JL, Molnar MZ, Ma JZ, Canada RB, Streja E, et al. Observational modeling of strict vs conventional blood pressure control in patients with chronic kidney disease. JAMA Intern Med. 2014;174(9):1442-9. https://doi.org/10.1001/jamainternmed.2014.3279. 
31. Cheung AK, Rahman M, Reboussin DM, Craven TE, Greene T, Kimmel PL, et al. Effects of Intensive BP Control in CKD. J Am Soc Nephrol. 2017;28(9): 2812-23. https://doi.org/10.1681/ASN.2017020148.

32. Ku E, Gassman J, Appel L, Smogorzewski M, Sarnak MJ, Glidden DV, et al. BP control and long-term risk of ESRD and mortality. J Am Soc Nephrol. 2017;28(2):671-7. https://doi.org/10.1681/ASN.2016030326.

33. Bansal N, McCulloch CE, Rahman M, Kusek JW, Anderson AH, Xie D, et al. Blood pressure and risk of all-cause mortality in advanced chronic kidney disease and hemodialysis: the chronic renal insufficiency cohort study. Hypertension. 2015;65(1):93-100. https://doi.org/10.1161/ HYPERTENSIONAHA.114.04334.

34. Appel LJ, Wright JT Jr, Greene T, Agodoa LY, Astor BC, Bakris GL, et al. Intensive blood-pressure control in hypertensive chronic kidney disease. N Engl J Med. 2010;363(10):918-29. https://doi.org/10.1056/NEJMoa0910975.

35. Adler Al, Stevens RJ, Manley SE, Bilous RW, Cull CA, Holman RR. Development and progression of nephropathy in type 2 diabetes: the United Kingdom prospective diabetes study (UKPDS 64). Kidney Int. 2003; 63(1):225-32.

36. Cushman WC, Evans GW, Byington RP, Goff DC Jr, Grimm RH Jr, Cutler JA, et al. Effects of intensive blood-pressure control in type 2 diabetes mellitus. N Engl J Med. 2010;362(17):1575-85. https://doi.org/10.1056/ NEJMoa1001286.

37. Pohl MA, Blumenthal S, Cordonnier DJ, De Alvaro F, Deferrari G, Eisner G, et al. Independent and additive impact of blood pressure control and angiotensin II receptor blockade on renal outcomes in the irbesartan diabetic nephropathy trial: clinical implications and limitations. J Am Soc Nephrol. 2005;16(10):3027-37.

38. Nicholas SB, Vaziri ND, Norris KC. What should be the blood pressure target for patients with chronic kidney disease? Curr Opin Cardiol. 2013;28(4):43945. https://doi.org/10.1097/HCO.0b013e32836208c2.

39. Whelton PK, Carey RM, Aronow WS, Casey DE Jr, Collins KJ, Dennison Himmelfarb C, et al. 2017 ACC/AHA/AAPA/ABC/ACPM/AGS/APhA/ASH/ ASPC/NMA/PCNA Guideline for the Prevention, Detection, Evaluation, and Management of High Blood Pressure in Adults: A Report of the American College of Cardiology/American Heart Association Task Force on Clinical Practice Guidelines. J Am Coll Cardiol. 2018;71(19):e127-248. https://doi.org/ 10.1016/j.jacc.2017.11.006 Epub 2017 Nov 13. Erratum in: J Am Coll Cardiol. 2018 May 15;71(19):2275-2279.

40. Plantinga L, Grubbs V, Sarkar U, Hsu CY, Hedgeman E, Robinson B, et al. Nonsteroidal anti-inflammatory drug use among persons with chronic kidney disease in the United States. Ann Fam Med. 2011;9(5):423-30. https://doi.org/10.1370/afm.1302.

41. Lipworth L, Abdel-Kader K, Morse J, Stewart TG, Kabagambe EK, Parr SK, et al. High prevalence of non-steroidal anti-inflammatory drug use among acute kidney injury survivors in the southern community cohort study. BMC Nephrol. 2016;17(1):189.

42. Zhan M, St Peter WL, Doerfler RM, Woods CM, Blumenthal JB, Diamantidis $\mathrm{CJ}$, et al. Patterns of NSAIDs use and their association with other analgesic use in CKD. Clin J Am Soc Nephrol. 2017;12(11):1778-86. https://doi.org/10. 2215/CJN.12311216.

43. Xie Y, Bowe B, Li T, Xian H, Yan Y, Al-Aly Z. Long-term kidney outcomes among users of proton pump inhibitors without intervening acute kidney injury. Kidney Int. 2017;91(6):1482-94. https://doi.org/10.1016/j.kint.2016.12. 021.

44. Xie Y, Bowe B, Li T, Xian H, Balasubramanian S, Al-Aly Z. Proton pump inhibitors and risk of incident CKD and progression to ESRD. J Am Soc Nephrol. 2016;27(10):3153-63.

45. Lazarus B, Chen Y, Wilson FP, Sang Y, Chang AR, Coresh J, et al. Proton pump inhibitor use and the risk of chronic kidney disease. JAMA Intern Med. 2016;176(2):238-46. https://doi.org/10.1001/jamainternmed.2015.7193.

46. Yang $\mathrm{H}$, Juang SY, Liao KF. Proton pump inhibitors use and risk of chronic kidney disease in diabetic patients. Diabetes Res Clin Pract. 2019 Jan;147:6775. https://doi.org/10.1016/j.diabres.2018.11.019.

47. Grams ME, Yang W, Rebholz CM, Wang X, Porter AC, Inker LA, et al. Risks of adverse events in advanced CKD: the chronic renal insufficiency cohort (CRIC) study. Am J Kidney Dis. 2017;70(3):337-46. https://doi.org/10.1053/j. ajkd.2017.01.050

48. Koraishy FM, Hooks-Anderson D, Salas J, Rauchman M, Scherrer JF. Fast GFR decline and progression to CKD among primary care patients with preserved GFR. Int Urol Nephrol. 2018;50(3):501-8. https://doi.org/10.1007/ s11255-018-1805-1.
49. Lipworth L, Mumma MT, Cavanaugh KL, Edwards TL, Ikizler TA, Tarone RE, et al. Incidence and predictors of end stage renal disease among lowincome blacks and whites. PLoS One. 2012;7(10):e48407. https://doi.org/10. 1371/journal.pone.0048407.

50. Peck RN, Smart LR, Beier R, Liwa AC, Grosskurth H, Fitzgerald DW, et al. Difference in blood pressure response to ACE-inhibitor monotherapy between black and white adults with arterial hypertension: a meta-analysis of 13 clinical trials. BMC Nephrol. 2013;14:201. https://doi.org/10.1186/1471-2369-14-201.

51. Agodoa LY, Appel L, Bakris GL, Beck G, Bourgoignie J, Briggs JP, et al. Effect of ramipril vs amlodipine on renal outcomes in hypertensive nephrosclerosis: a randomized controlled trial. JAMA. 2001;285(21):2719-28.

52. Rumsfeld JS, Joynt KE, Maddox TM. Big data analytics to improve cardiovascular care: promise and challenges. Nat Rev Cardiol. 2016 Jun;13(6): 350-9. https://doi.org/10.1038/nrcardio.2016.42.

53. Ellen ME, Leon G, Bouchard G, Ouimet M, Grimshaw JM, Lavis JN. Barriers, facilitators and views about next steps to implementing supports for evidence-informed decision-making in health systems: a qualitative study. Implement Sci. 2014;9:179. https://doi.org/10.1186/s13012-014-0179-8.

54. Matsushita K, Ballew SH, Astor BC, Jong PE, Gansevoort RT, Hemmelgarn BR, et al. Cohort profile: the chronic kidney disease prognosis consortium. Int J Epidemiol. 2013:42(6):1660-8. https://doi.org/10.1093/ije/dys173.

55. Jurkovitz CT, Qiu Y, Wang C, Gilbertson DT, Brown WW. The Kidney Early Evaluation Program (KEEP): program design and demographic characteristics of the population. Am J Kidney Dis. 2008 Apr;51(4 Suppl 2): S3-12. https://doi.org/10.1053/j.ajkd.2007.12.022.

56. Navaneethan SD, Jolly SE, Sharp J, Jain A, Schold JD, Schreiber MJ Jr, et al. Electronic health records: a new tool to combat chronic kidney disease? Clin Neph. 2013:79(3):175-83. https://doi.org/10.5414/CN107757.

57. HHS Launches President Trump's 'Advancing American Kidney Health' Initiative. July 10, 2019. https://www.hhs.gov/about/news/2019/07/10/hhslaunches-president-trump-advancing-american-kidney-health-initiative.html. Accessed 30 Aug 2019.

\section{Publisher's Note}

Springer Nature remains neutral with regard to jurisdictional claims in published maps and institutional affiliations.
Ready to submit your research? Choose BMC and benefit from:

- fast, convenient online submission

- thorough peer review by experienced researchers in your field

- rapid publication on acceptance

- support for research data, including large and complex data types

- gold Open Access which fosters wider collaboration and increased citations

- maximum visibility for your research: over $100 \mathrm{M}$ website views per year

At $\mathrm{BMC}$, research is always in progress.

Learn more biomedcentral.com/submission 